This item was submitted to Loughborough's Research Repository by the author.

Items in Figshare are protected by copyright, with all rights reserved, unless otherwise indicated.

\title{
A non-dimensional analysis of permeability loss in zero-valent iron permeable reactive barrier (PRB)
}

PLEASE CITE THE PUBLISHED VERSION

https://doi.org/10.1007/s11242-018-1096-0

\section{PUBLISHER}

(c) Springer Verlag

\section{VERSION}

AM (Accepted Manuscript)

\section{PUBLISHER STATEMENT}

This work is made available according to the conditions of the Creative Commons Attribution-NonCommercialNoDerivatives 4.0 International (CC BY-NC-ND 4.0) licence. Full details of this licence are available at: https://creativecommons.org/licenses/by-nc-nd/4.0/

\section{LICENCE}

CC BY-NC-ND 4.0

\section{REPOSITORY RECORD}

Santisukkasaem, Umarat, and Diganta Das. 2018. "A Non-dimensional Analysis of Permeability Loss in Zerovalent Iron Permeable Reactive Barrier (PRB)”. figshare. https://hdl.handle.net/2134/36238. 


\title{
A Non-dimensional Analysis of Permeability Loss in Zero-valent Iron Permeable Reactive Barrier (PRB)
}

Umarat Santisukkasaem, Diganta Bhusan Das*

Department of Chemical Engineering, Loughborough University, Loughborough LE11 3TU, Leicestershire, United Kingdom

(*Author for correspondence; Email: D.B.Das@lboro.ac.uk)

\begin{abstract}
Zero-valent iron (ZVI) permeable reactive barrier (PRB) is a treatment wall filled with $\mathrm{ZVI}$ as a reactive material that is installed perpendicular to the groundwater flow in the subsurface. To aid design of these PRBs, a non-dimensional analysis of the permeability reduction has been carried out in this work where the dimensionless equation has been identified to correlate different variables. Additionally, the change in physical features of ZVI PRB has been identified using the inspection system of x-ray microcomputer tomography $(\mu \mathrm{CT})$ and it has shown that the particle size is expanding, thus reducing the permeability. The change in chemical composition that impact the surface reactivity has been confirmed using $x$-ray diffraction (XRD) and the corroded products of maghemite and magnetite have been identified. Flow experiments have been conducted to observe and measure the changes in permeability, where the pressure at various points of the experimental rigs has been measured for the calculation of permeability values. The reduction in permeability could be observed from both small and large scale experiments. For example, the flow experiments indicated that the permeability value has been significantly reduced for coarse particle, e.g., in small scale experiment, it reduced from $7.04 \mathrm{E}-8$ to $3.09 \mathrm{E}-9 \mathrm{~cm}^{2}$. It can also be seen that the permeability is decreased by $95.6 \%$ for small scale (coarse particle) and by $79.5 \%$ for large scale.
\end{abstract}

Keywords: non-dimensional analysis; zero-valent iron; permeable reactive barrier; iron corrosion; permeability reduction

\section{Introduction}

Permeable reactive barrier (PRB) has been widely used in remediating contaminated groundwater for more than a decade (Battelle, 1998; Powell et al., 1998; Battelle, 2000; Wilkin et al., 2003; Chandrappa and Das, 2014; Huang et al., 2015; Li et al., 2015) and it is known that they are capable of carrying out treatment of large contaminant plumes passively and cost effectively. PRB is basically a porous wall filled with reactive material(s) that is installed perpendicular to the direction of groundwater flow. Zero-valent iron (ZVI) is the most commonly used reactive material (fillings) in PRB due to its high reactivity and suitability for removing various kinds of organic and inorganic compounds (Junyapoon, 2005; Thiruvenkatachari et al., 2008). However, one important limitation of ZVI PRB, which often hampers its long term performance, relates to the formation of mineral precipitates within the pores of the ZVI particles as a result of oxidation/corrosion reaction (Mackenzie et al., 1999; Furukawa et al., 2002; Li et al., 2005; Henderson and Demond, 2007; Philips et al., 2010; Ruhl et al., 2014). There is a significant amount of discussions that suggests that these precipitates are capable of inducing a coating on the surfaces of the ZVI particles and clogging the ZVI pores which subsequently limit the accessibility of contaminants to the 
reactive sites on the particles. These mineral precipitates reduce the overall porosity and permeability of the PRB (Jeen et al., 2006; Cundy et al., 2008; Jeen et al., 2012). They are therefore considered to have negative impacts on the performance of the ZVI PRB. Another factor which has been reported to contribute to the loss of permeability is gas formation in the PRBs. The oxidation of ZVI along with the reduction of the hydrogen ion or nitrate can cause gas formation, which reduces the permeability (Henderson and Demond, 2013). Several researches have been conducted to confirm the impacts of entrapped gas in anaerobic condition, sealed cells or with gas collection system (Reardon, 1995; Kamolpornwijit et al., 2003; Zhang and Gillham, 2005), which demonstrate that the gas affects the permeability in the specified conditions (e.g., sealed cells).

In the literature a number of other laboratory and field scale experiments involving PRBs have been reported. One of the vital aspects in carrying out these experiments is to provide fundamental understanding of how they function, so that the actual designs of PRBs can be accomplished in the field. The fluid flow in ZVI PRB can be defined as a single phase fluid flow (groundwater) through porous media governed by the intrinsic permeability $\left[\mathrm{m}^{2}\right]$ of the media (hence, the size and packing of the iron particles) and fluid pressure distributions. However, the underground system is complicated and there is a significant interference on the flow from a number of inter-dependent parameters. For example, the flow driving force depends on the pressure gradients not only in the PRB but also the surroundings (Das, 2002; Kaveh-Baghbaderani, 2009). Similarly, as the permeability decreases within the PRB, the flow gradient and direction within the PRB may change for given inlet flow boundary conditions. Therefore, a dimensional analysis of the permeability that provides a quantitative description of the behavior of the PRB in terms of dimensionless groups of relevant variables can be very useful (Bergendahl and Grasso, 2003; Abidoye and Das, 2014). In particular, the correlations that involve non-dimensional groups of measurable variables in the field (e.g., flow rate and fluid pressure) could be very useful to determine permeability (e.g., non-dimensional permeability) within the PRB.

Keeping the above issues in mind, an attempt is made in this work to analyze the permeability losses in ZVI PRB (laboratory scale system) using a series of well-defined experiments and dimensionless analysis of the permeability. The analysis is carried out by reducing the variables into dimensionless groups using the Buckingham $\pi$ theorem. This approach has the advantage that any variability of permeability due to changes in one particular parameter (e.g., particle size) is not of concern and we can analyse the permeability losses due to changes in groups of interrelated variables. This is expected to provide a correlation among the relevant variables (e.g., an upscaling relationship) as well as help analyse the experimental data.

In order to characterize the permeability losses in PRBs, several techniques have been applied at laboratory (small) scale PRBs, i.e., (a) imaging techniques (Ma et al., 2015), (b) estimation techniques (Furukawa et al., 2002; Jeen et al., 2006) and (c) direct measurements of permeability (Jeen et al., 2006). Imaging method, such as X-ray microcomputed tomography $(\mu \mathrm{CT})$, has been applied to image fluid distribution and pore morphologies in experimental PRBs without disturbing the sample. In the current work (this paper), $\mu \mathrm{CT}$ has been employed to observe the changes in $\mathrm{ZVI}$ particles as baseline condition (not corroded) and after the reaction with fluid in the experiment (corroded) and the X-ray diffraction (XRD) method has been used to identify the chemical 
components/phases in a sample. XRD indicates the X-ray diffraction patterns of the material that is like a fingerprint characterization of the crystalline materials present in a sample. The corroded products in ZVI have been analyzed and the secondary minerals have been identified (Ruhl et al., 2011; Yin et al., 2015) using these techniques. A great number of researches have also been conducted to determine the methods in impeding the corrosion rate and preventing the permeability loss, such as mixing of ZVI with other reactive materials, i.e., zeolites and calcites (Kim et al., 2013; Ruhl et al., 2013), sieving ZVI particles (Ruhl and Jekel, 2012) and ZVI depassivation (Luo et al., 2010).

The exact cause of permeability losses is irrelevant in the context of this work as the method is general and it can be applied to analyse the losses in all cases. However, for the purpose of this work, we demonstrate the approach for the case where the permeability loss is primarily due to mineral precipitation. This is because the gas formed due to corrosion reaction is vented off due to regular operation of the PRBs. The reactors have been designed in a manner so that the gas generated can migrate out of the system and any effect on the permeability reduction with respect to gas accumulation is defined to be negligible.

To carry out the planned analysis, we have conducted in-house experiments on the permeability losses in ZVI PRB and the corrosions of the ZVI particles are confirmed by using $\mu C T$ and XRD as discussed above. This paper introduces these experimental results along with the non-dimensional analysis.

\section{Materials and Methods}

\subsection{Materials}

Zero valent iron (ZVI) fillings used in this work were obtained from Connelly-GPM, Inc., Illinois, USA, which are referred as ETI CC-1004 (coarse particles) and CC-1200 (fine particles) with the average particle size of $2.35 \pm 0.01 \mathrm{~mm}$ and $0.40 \pm 0.01 \mathrm{~mm}$, respectively (Figure 1). The particles have the same chemical compositions but different sizes. They are composed of a maximum of $93 \%$ metallic iron/iron oxide while the rest of the components include total carbon, manganese, sulphur, phosphorus, silicon, nickel, chromium, molybdenum, titanium, copper, aluminum and a negligible amount $(0.01 \%$ each) of magnesium, boron, zinc and zirconium. The particle density has been determined in-house by using pycnometer, which indicated a material density of $7.25 \mathrm{~g} / \mathrm{cm}^{3}$. 


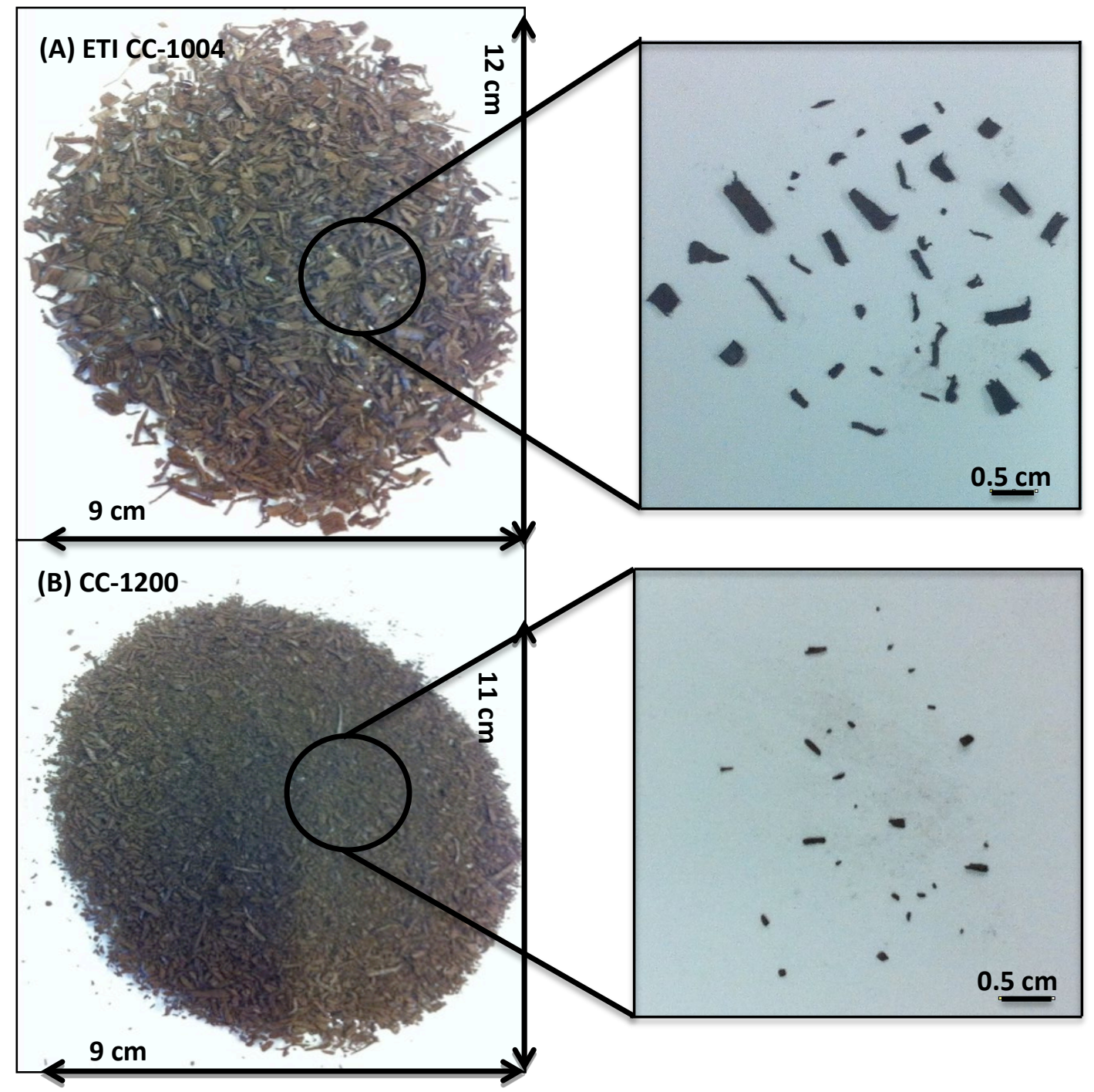

Figure 1: Physical appearances of zero-valent iron and the magnification: (A) ETI CC-1004 coarse particle size $(0.15-4.75 \mathrm{~mm})$ and (B) CC-1200 fine particle size $(0.075-0.85 \mathrm{~mm})$

\subsection{Methods}

\subsubsection{Confirmation of the Corrosion of ZVI Particles}

In order to confirm that the chosen ZVI particles undergo corrosion reactions, the following procedures were followed.

Cylindrical tubes of diameter of $1.2 \mathrm{~cm}$ and length of $13 \mathrm{~cm}$ were packed with fine ZVI particles with the porosity of 0.63 , fine $\mathrm{ZVI}$ particles was selected to confirm the corrosion and as both coarse and fine particles have identical chemical composition, it is then assumed that they will react in the same manner. Figure 2 illustrates the empty and packed cylindrical tubes. The packed cylinders are analyzed without (dry) and with tap water (wet) for a period of 1 month, which represent the cases where the ZVI is 'not corroded' and 'corroded', respectively. The tubes were scanned using the floor standing, real-time X-ray microcomputer tomography $(\mu \mathrm{CT}$ ) inspection system (XT H 160, Metris, Nikon Metrology UK Ltd., Nottingham, United Kingdom) to capture the internal features of ZVI samples. The 
images at different slides were then used to determine the changes in microscopic features by using the software ImageJ (Institutes of Health, Bethesda, Maryland, USA).

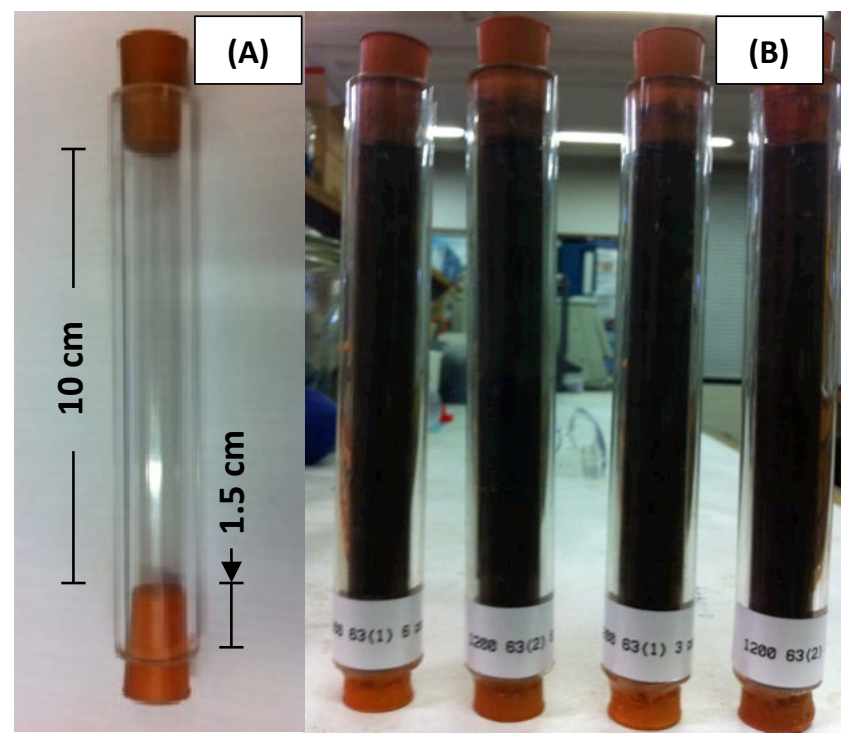

Figure 2: Dimension of the cylindrical tube (A) and packed tubes with fine ZVI materials (B)

The ZVI samples of both particle sizes were prepared where two samples for each of (1) original, (2) medium term and (3) long term, i.e., a total of 12 samples were taken for XRD measurements. The original sample is dry ZVI as received to be used as the baseline. The medium term sample is the one where ZVI has been in contact with stagnant water representing batch experiment for 1 month and dried in a vacuum desiccator without any additional heating. The long term sample is the one collected from the lab-scale column experiment where ZVI has been in contact with continuous flowing water for 3 months representing column experiment. The phases of the dried samples were identified by XRD equipped with Cobalt anode (Philips PW 3710 Expert, Philips). In the XRD analysis, the degree was set at 2-theta-range of $10^{\circ}-70^{\circ}$ and scanned at the step size of $0.014^{\circ}$ for 1.5 seconds.

\subsubsection{Experimental Setup}

In order to obtain in-house data on the permeability losses during flow through the PRB, the following column experiments have been carried out. The experiments have been setup for two different scales, namely, small and large scales.

Figure 3 illustrates the small scale experimental setup where the peristaltic pump (Masterflex, Cole-Palmer Instrument Co., LLC, London, UK) is used to flow the water through the rig packed with the $\mathrm{ZVI}$ materials. The rig is drilled with 4 ports, e.g., $\mathrm{P}_{1}, \mathrm{P}_{2}, \mathrm{P}_{3}$ and $\mathrm{P}_{4}$, which were used to measure fluid pressures. The gas generated in the system can migrate out of the domain when the pressure measuring ports are opened; therefore no specific venting system was installed in the PRB. The rig is made up of acrylic square tubes with the dimensions of $10 \mathrm{~cm} \times 4.50 \mathrm{~cm} \times 4.50 \mathrm{~cm}$ (height $x$ width $x$ length) and with a wall thickness of $0.63 \mathrm{~cm}$. The rig was packed with both coarse and fine ZVI particles, separately. The initial porosity of the packed rig was 0.52 for fine ZVI particles and 0.62 for coarse ZVI particles. 
(a)

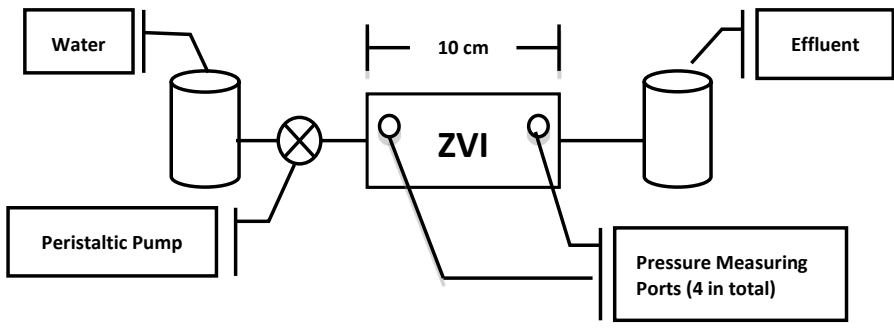

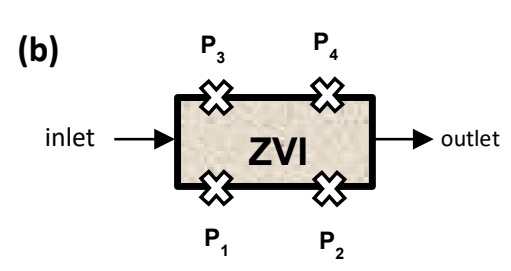

Figure 3: The schematic diagram of the small scale experimental setup (a) and the top view of the location of the pressure measuring ports (b)

(a)

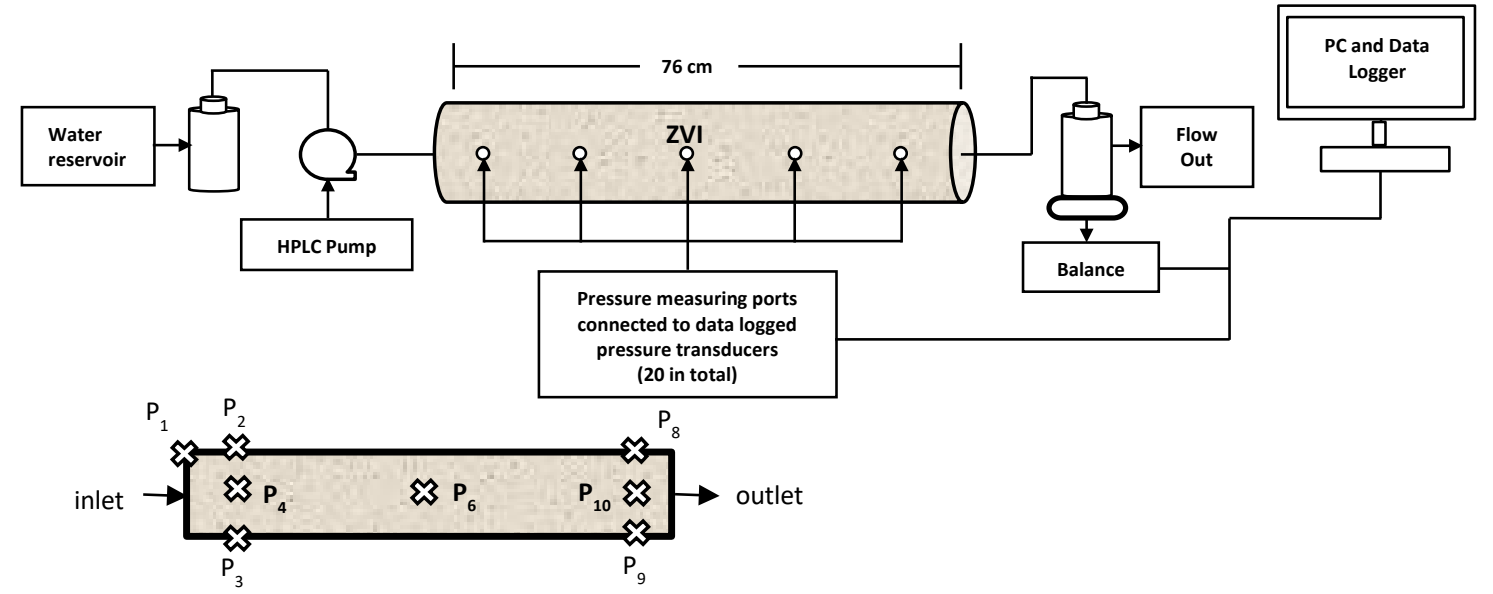

Remarks: $P_{5}$ is opposite to $P_{4}$ and $P_{11}$ is opposite to $P_{10}$

Figure 4: A schematic diagram of the large scale experimental setup (a) and the side view of the location of the pressure measuring ports (b)

The larger scale rig as displayed in Figure 4 is made up of cylindrical acrylic column with the length of 76 centimetres and the internal diameter of 14 centimetres. There is a space between the inlet from the pump and the PRB area with the port situated on top of the rig where the port can be opened to release any gas trapped inside the reactor. It was packed with the fine ZVI particles and had an initial porosity of 0.46 . A HPLC pump is used to feed the water solution through the rig equipped with 20 ports for pressure measurements.

The water was pumped through the two rigs in the axial direction at the initial flow rate of $0.29 \mathrm{~mL} / \mathrm{min}$ and $0.25 \mathrm{ml} / \mathrm{min}$ for small and large scale rigs, respectively. For the small rig, the fluid pressure was manually measured using pressure gauges (meters) at different time intervals from the 4 measuring ports of $P_{1}$ to $P_{4}$. The fluid pressures in the large rig was automatically measured using data-logging software of $\mathrm{NI}$ SignalExpress, National Instruments Corporation, Austin, Texas, United States; and pressure transducers at hourly intervals from 20 pressure measuring ports in the column. The recorded data were selected from several pressure measuring points which were representative of the whole rig. The flow rate at the outlet was measured using cylinder and container on balance for both small and large rigs, respectively.

The flow in the rig is primarily in the axial direction although the fluid may be distributed in the radial directions. Nevertheless, the permeability in the axial direction is calculated from 
Darcy's law (Holdich, 2002) using the measured data from both the experiments. The rearrangement of Darcy's law to determine this permeability is shown in equation (1).

$$
\mathbf{k}=\frac{\mathbf{Q} \mu \Delta \mathbf{x}}{\mathbf{A} \Delta \mathbf{P}}
$$

Where, $k$ is the 1D permeability $\left(\mathrm{cm}^{2}\right)$ in the axial direction, $Q$ is the outlet flow rate $\left(\mathrm{cm}^{3} / \mathrm{s}\right)$, $\mu$ is the viscosity $(\mathrm{g} / \mathrm{cms}), \Delta x$ is the distance between two pressure measuring points $(\mathrm{cm})$ in the axial direction and $\Delta \mathrm{P}$ is the differential pressure in axial direction $\left(\mathrm{g} / \mathrm{cms}^{2}\right)$, i.e. calculated from pressure value at reference point $P_{2}$ minus pressure value at reference point $\mathrm{P}_{1}$.

\subsubsection{Buckingham $\pi$ Theorem for Non-dimensional Analysis of Permeability Loss}

The Buckingham $\pi$ theorem is applied in this work to identify the dimensionless permeability (or dimensionless permeability loss) in the PRBs. According to the theorem dimensionless groups can be determined from the independent variables involved in a process, namely, permeability loss in this case. As there are a number of interrelated variables in the process, it is complex to define the relationships between the parameters and the permeability loss. Therefore, the $\pi$ theorem is applied so as to form dimensionless groups of variables. The theorem basically provides a number of dimensionless groups that has an impact on the process but it does not give the correlation coefficients directly. These coefficients will be determined from the experimental data obtained in this work.

The non-dimensional analysis is composed of three main steps, namely, (1) identifying the dimensional quantities $(r)$ of the variables, i.e. mass $(M)$, length $(L)$ and/or time $(T)$, where value of $r$ is also the number of repeating variables, (2) identifying the number of variables $k$ and the number of dimensionless group or $\pi$ term $p$ equalling $k-r$ and (3) carrying out a dimensional analysis. The flow in the ZVI-PRB behaves as single phase flow through porous medium where the important variable of $k$ or permeability is dependent on several parameters.

The permeability is the ability of the porous materials that allows the fluid to flow through. In the determination of permeability $(k)$ value in the analysis, $k$ is defined as the dependent variable and that it is affected by various independent variables. As shown in equation (2), the selected independent variables are flow rate $(Q)$, viscosity $(\mu)$, axial distance between points of pressure change $(\Delta x)$ and pressure change $(\Delta P)$ between these points.

$\mathrm{k}=f(\mathrm{Q}, \mu, \Delta \mathrm{x}, \Delta \mathrm{P})$

The flow rate $(Q)$ of the fluid flowing out of the reactive zone, i.e. the porous materials, is chosen for dimensional analysis because the decreasing of the flow rate reflects that there is a blockage or clogging of the pores of the porous materials and, thus, a reduced permeability. The viscosity $(\mu)$ of the liquid represents one of the fluid properties. When there are the changes in the permeability, there is a resistance to the fluid flow. This has a direct impact on the pressure change as the pressure differences increase as the resistance increases. In addition, the pressure change varies depending on the distance of the measured points. Therefore, the pressure change $(\Delta \mathrm{P})$ and the distance between points of pressure change $(\Delta x)$ are defined as the other important relevant parameters. Table 1 has listed the selected dependent and independent variables with their units and dimensions. 
Table 1: The selected variables and their dimensions

$\begin{array}{lcc}\text { Dependent and Independent Variables } & \text { Unit } & \text { Dimension } \\ \text { Permeability }(\mathrm{k}) & \mathrm{cm}^{2} & \mathrm{~L}^{2} \\ \text { Outlet flow rate }(\mathrm{Q}) & \mathrm{cm}^{3} / \mathrm{s} & \mathrm{L}^{3} / \mathrm{T} \\ \text { Viscosity }(\mu) & \mathrm{g} / \mathrm{cm}-\mathrm{s} & \mathrm{M} / \mathrm{LT} \\ \text { Distance between 2 pressure points }(\Delta \mathrm{x}) & \mathrm{cm} & \mathrm{L} \\ \text { Pressure changes }(\Delta \mathrm{P}) & \mathrm{g} / \mathrm{cm}-\mathrm{s}^{2} & \mathrm{M} / \mathrm{LT}^{2}\end{array}$

The Buckingham $\pi$ theorem has been adopted for the non-dimensional analysis of these variables. As there are 5 variables $(k, Q, \mu, \Delta x$ and $\Delta P$ ) with 3 dimensions $(M, L, T)$, the $\pi$ term is equal to 2 . The general form of the relationship between the two $\pi$ terms can therefore be written as shown in equation (3).

$\pi_{1}=\boldsymbol{f}\left(\pi_{2}\right)$

After selecting the repeating variables and carrying out an analysis, the following two dimensionless groups are identified:

$\pi_{1}=\frac{k}{\Delta x^{2}}$

$\pi_{2}=\frac{\mu Q}{\Delta x^{3} \Delta P}$

$\boldsymbol{\pi}_{\mathbf{1}}$ represents the non-dimensional permeability of the PRB while $\boldsymbol{\pi}_{\mathbf{2}}$ represents the nondimensional flow rate of fluid leaving the PRB. Rearranging both $\pi$ terms into the equation (3), the dimensionless groups are related as shown in equation (6).

$\frac{k}{\Delta x^{2}}=f\left(\frac{\mu Q}{\Delta x^{3} \Delta P}\right)$

The values of the dependent variables of $Q, \mu, \Delta x$ and $\Delta P$ are measured from the experiment taking into account different pressure points, different distances between the pressure points as well as different time durations, which give different values of outlet flow rate. The permeability value $k$ is calculated from Darcy's law (equation 1 ) for both small and large scale which are used for equation 6.

\section{Results and Discussions}

\subsection{Confirmation of the Corrosion of ZVI Particles and Changes in the Pore Space}

Typical $\mu \mathrm{CT}$ images which show the packing of the ZVI particles are shown in Figure 5 . The software ImageJ is deployed to analyse the selected slides from the images for both wet and dry ZVI particles. 

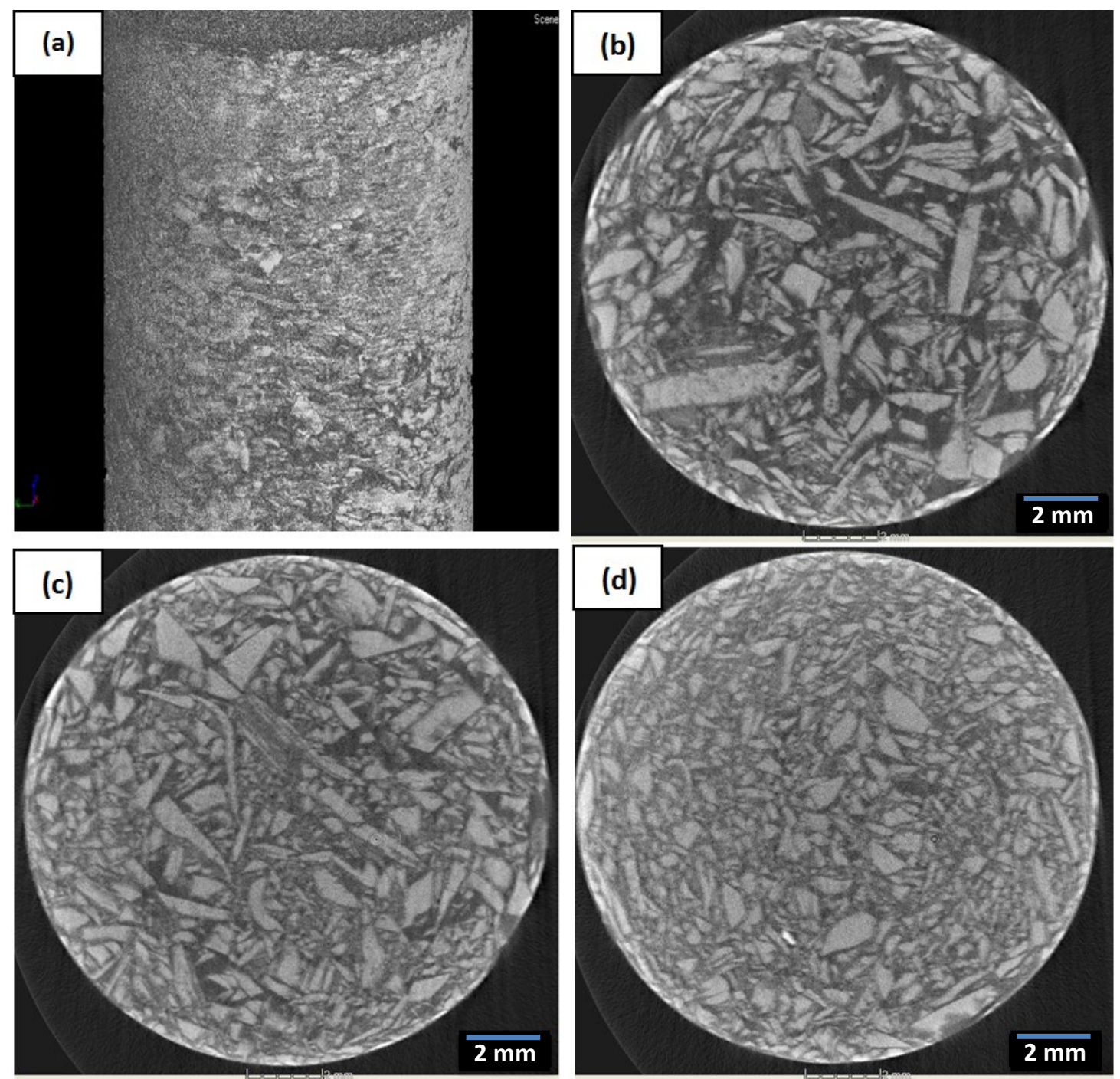

Figure 5: Typical images of fine ZVI particle: (a) 3D overview; (b),(c) and (d) top views at different levels of the tube

The horizontal cross-section (Fig. 5b-5d) of 3D image (Fig. 5a) were taken using the clipping tool and processed with ImageJ using adjustment of colour threshold, e.g., see a typical image as indicated in Figure 6 . ImageJ is adopted to determine the average particle size from the randomly selected slides of the fine $\mathrm{ZVI}$ particle images captured by $\mu \mathrm{CT}$. For example, Figures 7 and 8 illustrate the particle size distribution for fine ZVI particle (dry and wet) respectively, as determined from ImageJ. ImageJ determined the particle area of the ZVI particles in the unit of $\mathrm{mm}^{2}$ and expressed the repetitive area (counts) in percentage. 


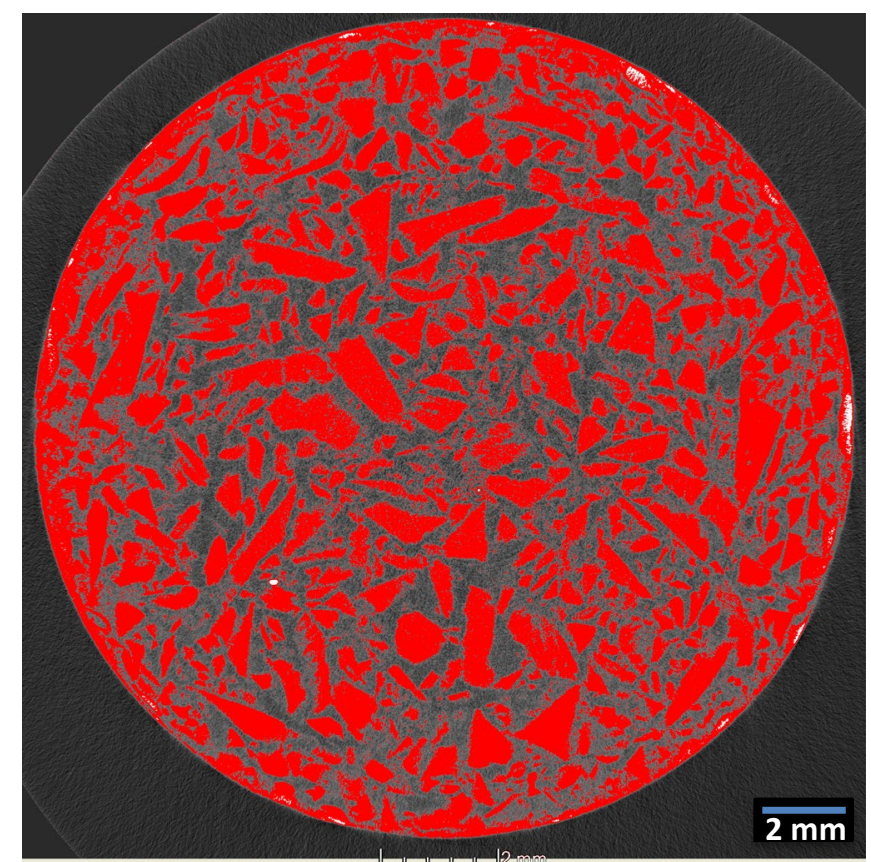

Figure 6: A sample of colour threshold adjusted photo prepared using ImageJ for particle area determination

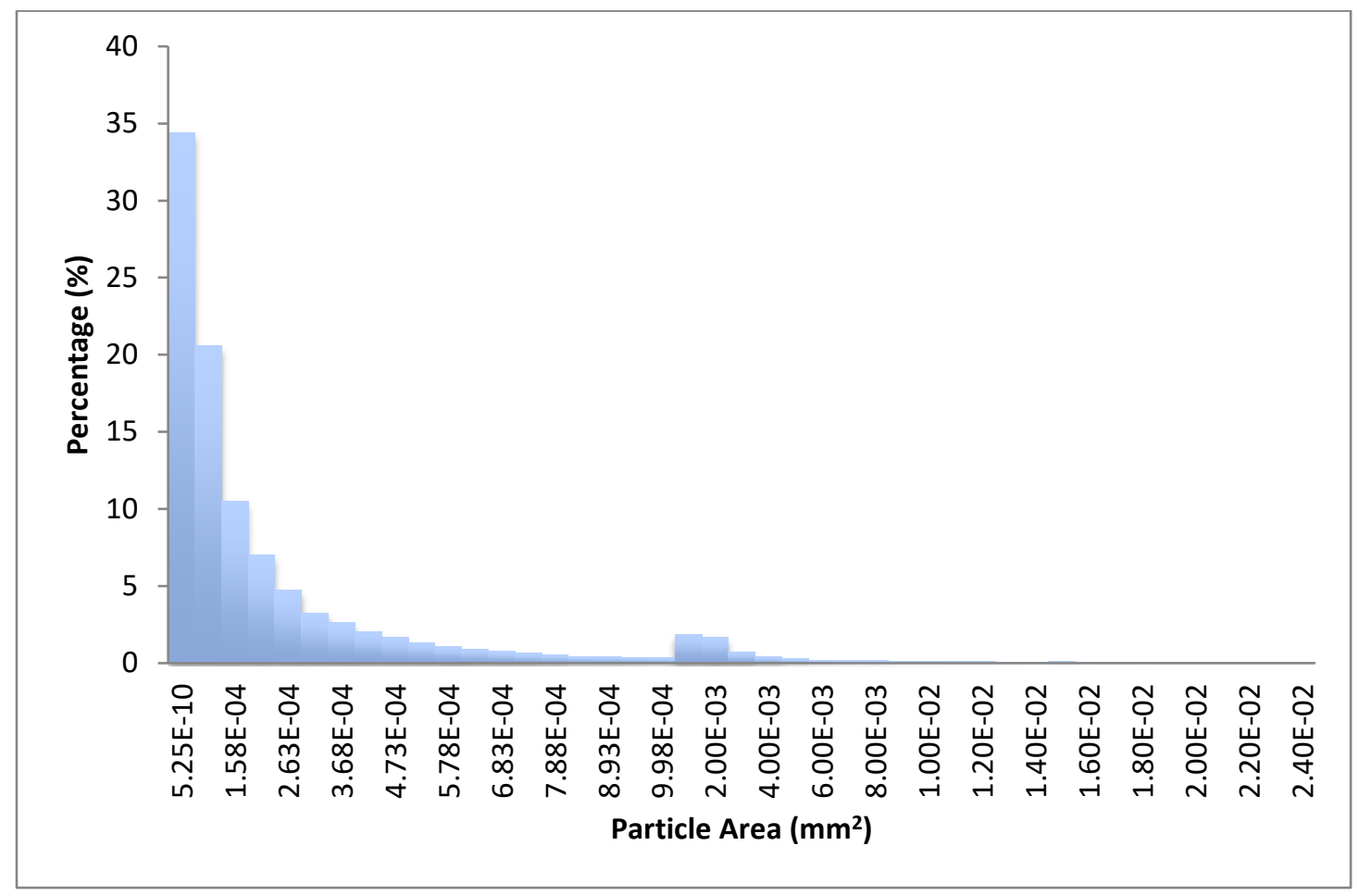

Figure 7: A plot of typical particle size (area) distribution of dry fine ZVI particle between the particle area $\left(\mathrm{mm}^{2}\right)$ on the $x$-axis versus the percentage (\%) on the $y$-axis 


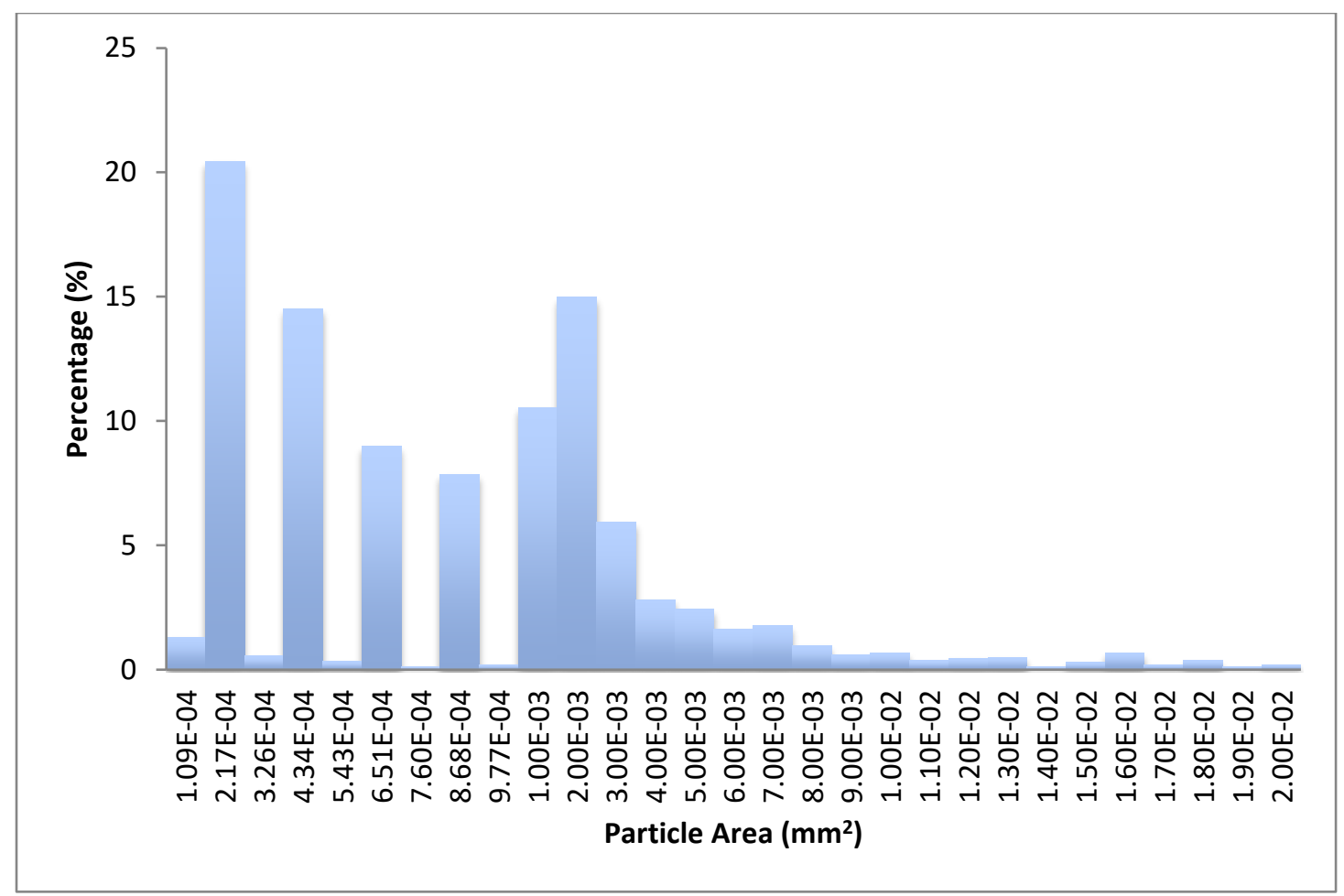

Figure 8: A plot of typical particle size (area) distribution of wet fine ZVI particle between the particle area $\left(\mathrm{mm}^{2}\right)$ on the $x$-axis versus the percentage (\%) on the $y$-axis

As the wet and dry tubes are prepared separately but simultaneously to simulate the before (baseline) and after (in contact with fluid, i.e. corroded) scenarios, the particle area for the same slide could not be compared directly. However, both tubes were prepared in the same manner, i.e., they were packed with the same ZVI materials and had the same porosity. For example, using the particle area of $0.001 \mathrm{~mm}^{2}$ as a reference point, it can be seen that there is only $54 \%$ of the wet particle that is higher than that limit, i.e., further to the right of the referenced value; but, it is as high as $94 \%$ in the case of dry particle. The average particle size of the wet particle is significantly increased by factor of two. It can be suggested from the increasing values that after the ZVI particle has been in contact with water and the corrosion reactions occurred on the surface of the particles, thus increasing the particle size or/and reducing the pore space.

The main chemical components identified by search/match procedure from XRD diffraction pattern are (1) iron (2) maghemite and (3) magnetite. Maghemite and magnetite are expected to be identified by XRD as they are the iron oxides that occurred from the reduction of iron in water. This observation is in line with the research by Kohn et al. (2005) who reported that the main phases found from iron columns were magnetite or maghemite. In addition, Li et al. [12] found that magnetite is the most common minerals precipitated in ZVI PRB. The diffraction pattern of the original sample for coarse particle is shown in Figure 9. 


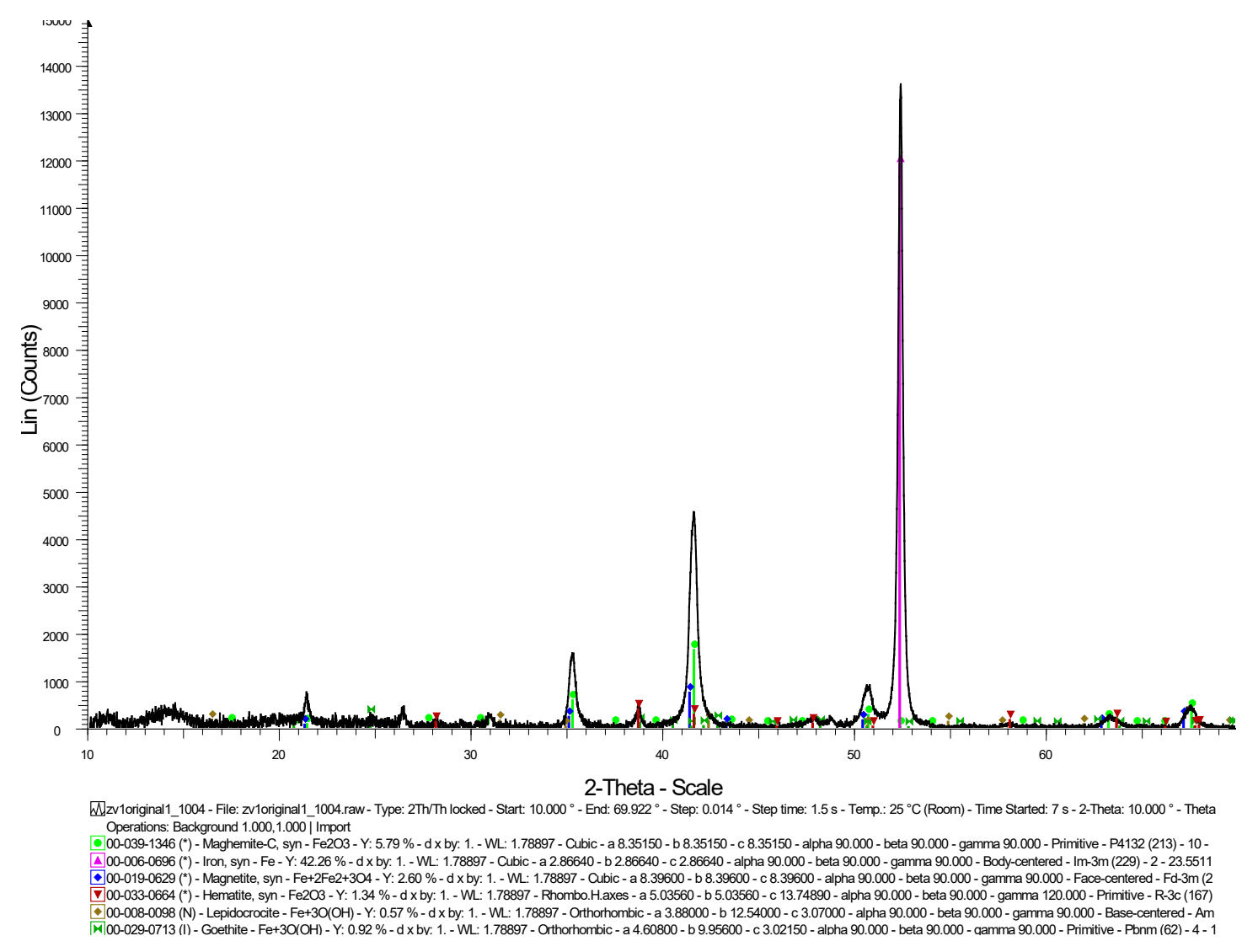

Figure 9: A typical XRD pattern of ZVI particle

The coarse particle has been selected to discuss as it is more sensitive compared to the fine particle due to the fact that the changes in the corrosion product are much more apparent. Figure 10 shows that ZVI has been oxidized to other compounds as the height of the peak reflects the amount of the particular compound. As evident the height of the peak has decreased from 13600 counts to 5400 and 3500 counts for medium and long term samples, respectively. This behaviour is the same for the 3 compounds detected: maghemite and magnetite are also reduced in the same way. Overall, it can be implied that the corrosion products of Maghemite and Magnetite are generated after the reaction has been occurred. These products have altered the physical features of the $\mathrm{ZVI}$, thus affecting the properties of the ZVI particle packing.

\subsection{Changes in Outflow}

The main factor which indicates the changes in the permeability is the fluid flow (e.g., outlet flow) through the porous medium and fluid pressures at different points, while the same fluid pressures are maintained at the boundary of the PRB. In this work, the experiment has been designed to maintain the relevant parameters constant, i.e. fluid viscosity and height/area of the rig along the flow, and observe how the permeability decreases.

Figure 11 shows a plot of the flow rate at the outlet $(\mathrm{mL} / \mathrm{h}$ ) versus time duration (day) for coarse and fine ZVI particles from small and large scale experiments. It can be seen that the flow rate is continuously decreasing through time in both the cases. For the fine ZVI particles, there was a minor difference in the initial flow rate but both the scales reflected 
similar reduction to approximately $8 \mathrm{~mL} / \mathrm{h}$ but for the coarse particles, the flow rate has reduced to $1 \mathrm{~mL} / \mathrm{h}$. The reduction in flow rate shows that for given pressure gradient, the resistance for liquid flow through the $Z \mathrm{VI}$ increases. This suggests that precipitates have occurred due to corrosion reactions, which have blocked the flow pathways resulting in decreasing flow ability. The local pressure gradient $(\Delta \mathrm{P} / \Delta \mathrm{x})$ gradually increases as the pore diameter decreases due to mineral precipitates in the pore (partial pore blockage).

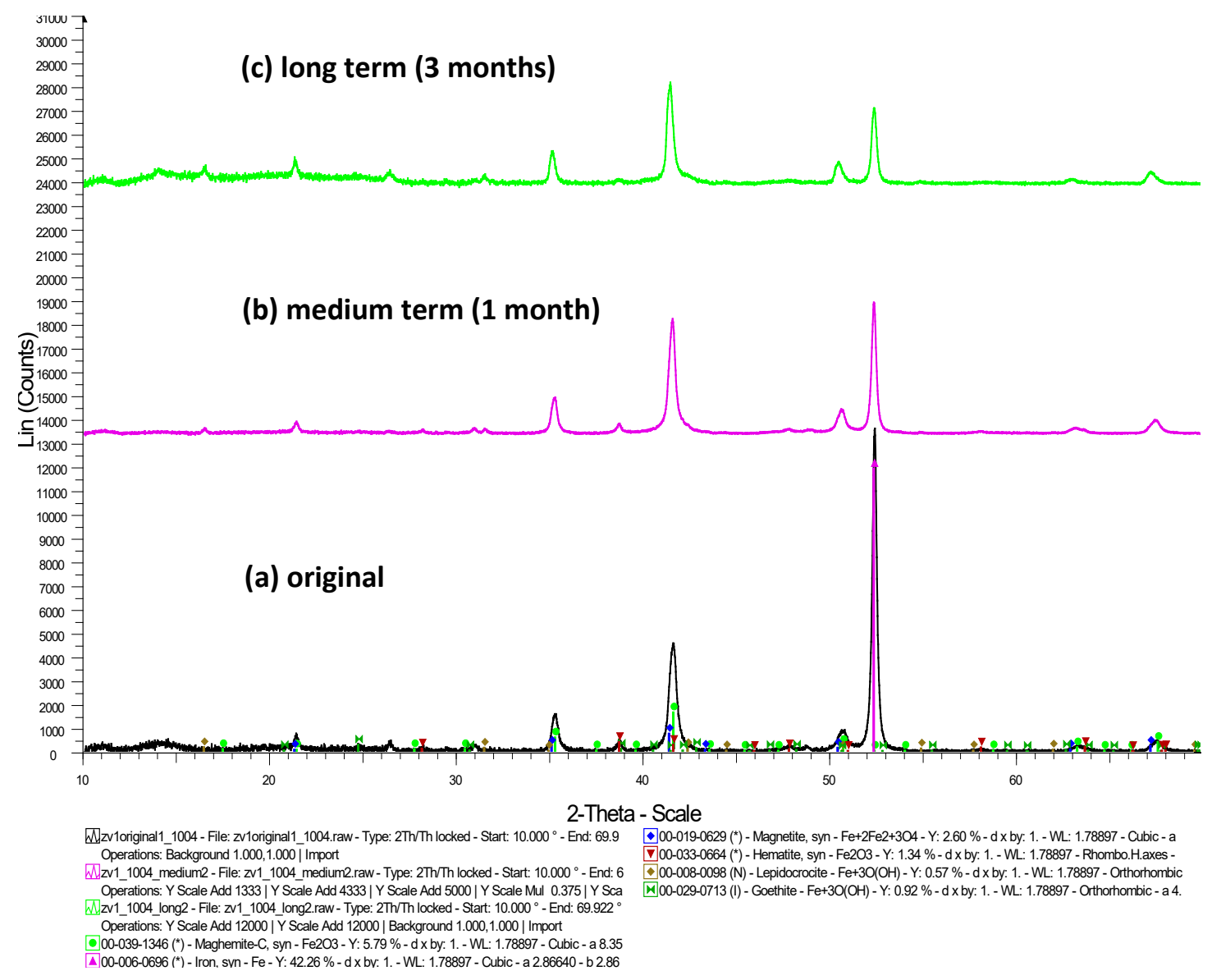

Figure 10: XRD pattern of coarse ZVI particle under 3 different conditions: (a) original, shown in black; (b) medium term, shown in pink and (c) long term, shown in green

\subsection{Changes in Pressure Gradient in Lateral Direction}

Although the flow is in the axial direction along the length of the rig, the pressure distribution in the lateral directions also provides interesting insights. In particular it may provide some useful understanding on when the pores start to get blocked significantly. This is because preferential flow in the lateral directions may take place instead of the flow in the axial directions. To understand this, let us consider the pressure gradients from 4 reference points, i.e. close to the inlet and outlet, which are selected from both the small and large scale rigs to determine the pressure gradient as shown in Figure 12. According to Figure 12, the pressure gradient at the location close to the inlet is denoted in blue, P13 and P45 for small and large scale experiment, respectively, and the red colour represents the data taken at the location close to the outlet. 


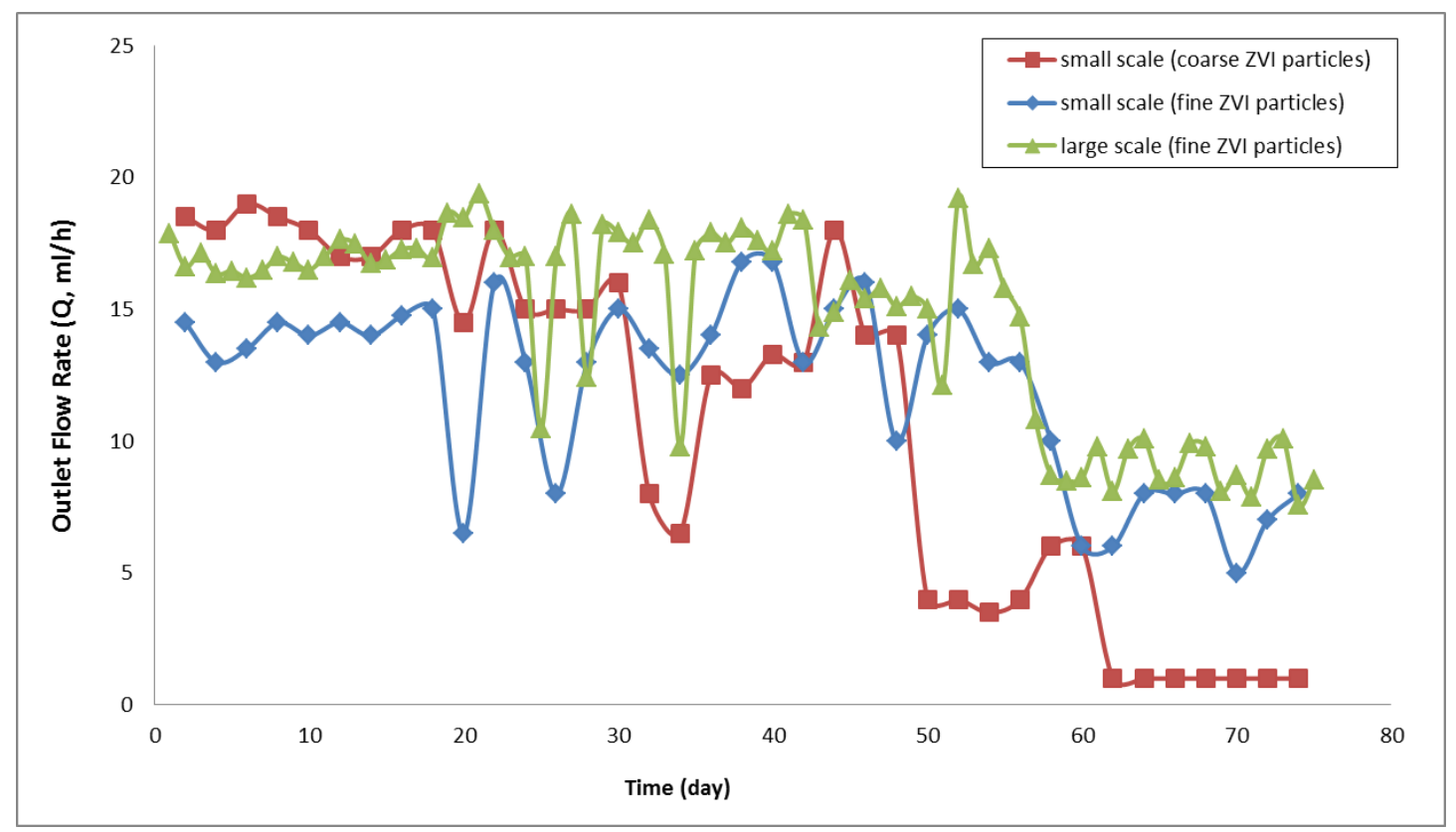

Figure 11: A plot of outlet flow rate $(\mathrm{ml} / \mathrm{h})$ versus time $(\mathrm{d})$ for coarse and fine $\mathrm{ZVI}$ particles in small and large scale experiments

In small scale experiment (Figures $12 \mathrm{a}$ and $12 \mathrm{~b}$ ), there is not much difference in pressure gradient near the inlet and outlet at the beginning. However, the values at the beginning of the experiment (i.e., when $\mathrm{ZVI}$ are not corroded) are significantly different for different particle size, e.g., it is approximately $+1 \mathrm{mbar} / \mathrm{cm}$ in fine particles and it is only around 0.1 $\mathrm{mbar} / \mathrm{cm}$ in coarse particles. As the flow is continued, the changes start to take effect around the inlet after approximately 20 days for both particle sizes when the pressure gradient start to increase significantly in the lateral directions. We attribute this to the blockage of the flow in the axial direction. This also means that the preferential fluid flow may take place in the lateral directions.

The pressure gradient tends to decrease with respect to time as well. The possible reason behind this could be the preferential flow behaviour (e.g., after 60 days) that may create a flow channel between the packed materials, thus no pressure is required to support the flow. On the other hand, the coarse particles indicate the obvious trend that is in line with the theory as the overall pressure gradients from both the locations (inlet and outlet) have the same trends, i.e., they are increasing with respect to time.

For the large scale experiment (Figure 12c), there is a significant difference in the lateral pressure gradient at the very first day that it is much higher at the outlet, approximately $+0.8 \mathrm{mbar} / \mathrm{cm}$ than at the inlet. This is mainly due to the distance between the inlet and the outlet which is about 10 times longer in large rig compared to the small rig. It is harder to pack and tab the materials which may cause the rig to be non-homogeneously mixed. In comparison with the coarse particle in small scale experiment, the large scale rig has not clearly reflected the rate of pressure changes with respect to time but it is similar to the fine particles in the small scale experiment. This indicates that the particle size is one of the important parameter in determining the flow behaviour. Overall, it seems that the coarse particle reflects that the pressure gradient is increasing with respect to time which means that there is a preferential flow causing changes in permeability. 

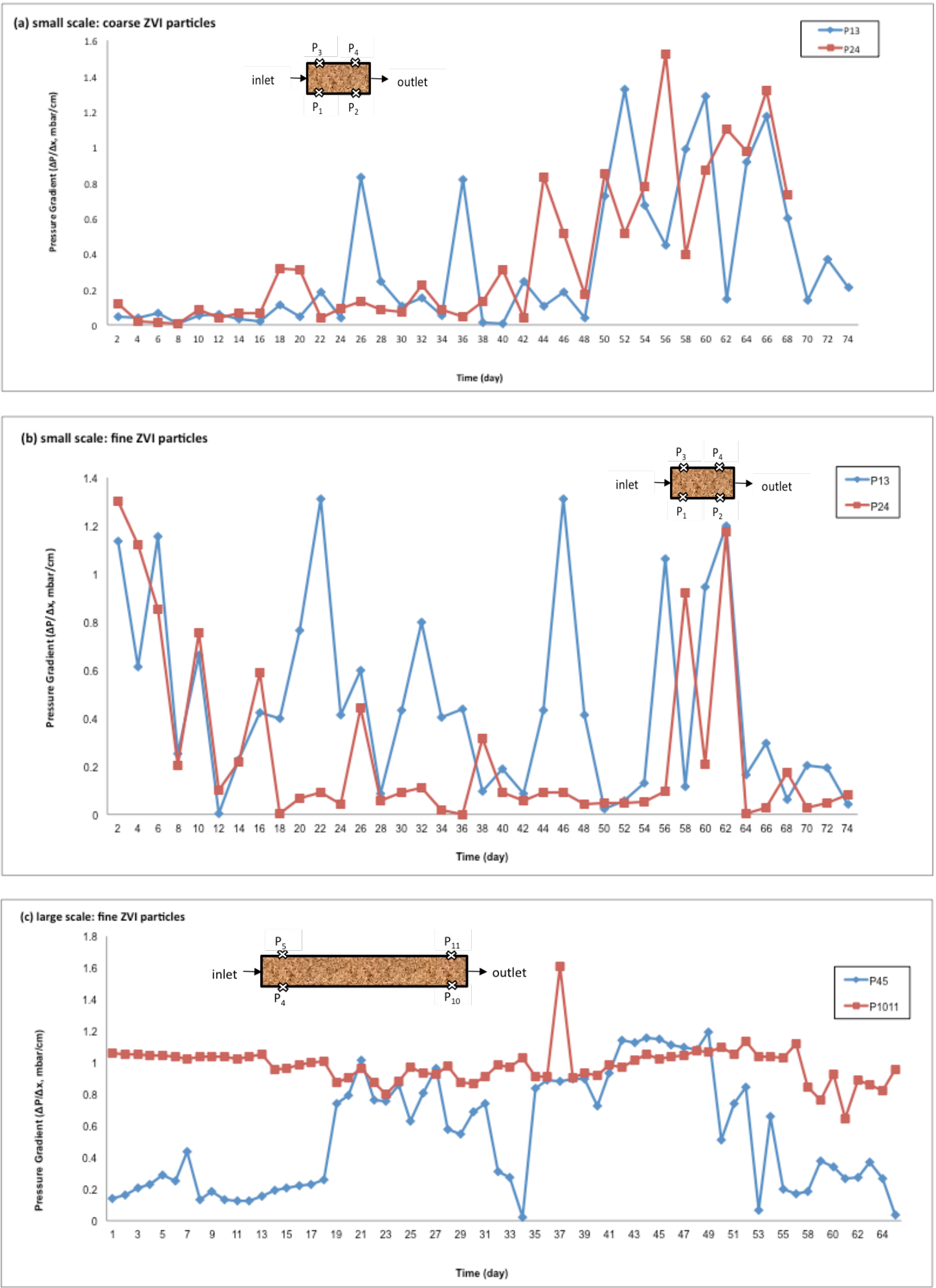

Figure 12: A plot of the pressure gradient $(\Delta \mathrm{P} / \Delta \mathrm{x}, \mathrm{mbar} / \mathrm{cm})$ in the lateral flow direction with respect to time (day) for coarse and fine $\mathrm{ZVI}$ particles in small and large scale experiments where (a) small scale: coarse particles; (b) small scale: fine particles and (c) large scale: fine particles 


\subsection{Changes in Permeability Values}

The permeability $(k)$ reflects the ability of the fluid to flow through the porous medium. In this work, the permeability values are calculated from the directly measured data from the experiment using equation (1). Figure 13 illustrates the plot of permeability versus time for (a) coarse ZVI particle and (b) fine ZVI particle from small scale experiments. The data of P12 and P34 are measured in the axial direction. The permeability changes through time are not constant and it seems to vary. This can be due to the impact of the non-uniform packing of ZVI materials and/or the non-uniform particle size of the material itself as some part of the particles might be densely packed while some part might be loosely packed. Secondly, the distance between the pressure measurement ports is small, thus there is not much pressure difference. In addition, the measurement has been performed at very low level (millibar), which may fluctuate from one measurement to another. However, it is still observed that the permeability is decreasing with respect to time in the case of coarse particle size where the average permeability from the two reference points has dropped from $7.04 \mathrm{E}-8 \mathrm{~cm}^{2}$ to $3.09 \mathrm{E}-9 \mathrm{~cm}^{2}$. The permeability seems to increase in the case of fine particle from $8.39 \mathrm{E}-9 \mathrm{~cm}^{2}$ to $2.12 \mathrm{E}-8 \mathrm{~cm}^{2}$ which indicates possibility of non-uniform packing and some preferential flow in the domain.

The permeability from large scale experiment is displayed in Figure 14 . The data points of P28, P39, P410 and P511 are measured in the axial direction. It can be seen from the Figure 14 that the permeability values fluctuate less as compared to that of the small scale. The average permeability is also reduced with respect to time from $5.27 \mathrm{E}-9 \mathrm{~cm}^{2}$ to $1.08 \mathrm{E}-9 \mathrm{~cm}^{2}$. It is noticed that the permeability at a comparable reference point, i.e. in the axial direction but taken from different locations as from different sides of the rig or from top or bottom of the rig is different. For example for fine particle size, it is approximately $1 \mathrm{E}-8 \mathrm{~cm}^{2}$ and $6 \mathrm{E}-$ $9 \mathrm{~cm}^{2}$ for small scale and it varied from $1 \mathrm{E}-9 \mathrm{~cm}^{2}$ to $1 \mathrm{E}-8 \mathrm{~cm}^{2}$ for large scale. Even though it is a negligible difference this can be explained according to the fact that the ZVI cannot be homogeneously packed.

The initial and final permeability values from both small and large scale are summarized in Table 2. The combination of permeability data at each reference point yields the average initial permeability for coarse particle size from small scale experiment of 7.04E-8 and for fine particle size are $8.39 \mathrm{E}-9 \mathrm{~cm}^{2}$ and $5.27 \mathrm{E}-9 \mathrm{~cm}^{2}$ for small and large scale experiment, respectively. The arithmetic mean is adopted to calculate the average permeability. The flow experiments caused the changes in permeability values and indicated that the permeability has been reduced to $3.09 \mathrm{E}-9 \mathrm{~cm}^{2}$ for small scale (coarse particle) and $1.08 \mathrm{E}-9$ $\mathrm{cm}^{2}$ for large scale (fine particle). It is apparent that the permeability values for both experiments fall in the same range and decrease in the same trend. It is only in the small scale (fine particle) that the permeability tends to increase through time, i.e. from $8.39 \mathrm{E}-9$ to $2.12 \mathrm{E}-8 \mathrm{~cm}^{2}$.

By calculating the percentage of the permeability loss, it can be seen that the permeability is decreased by $95.6 \%$ for small scale (coarse particle) and by $79.5 \%$ for large scale. The experiment has been operated in the duration of about 3 to 6 months but the permeability has been reduced to almost $100 \%$ in the case of small scale. This explains further the reduction in flow rate from the previous discussion. 

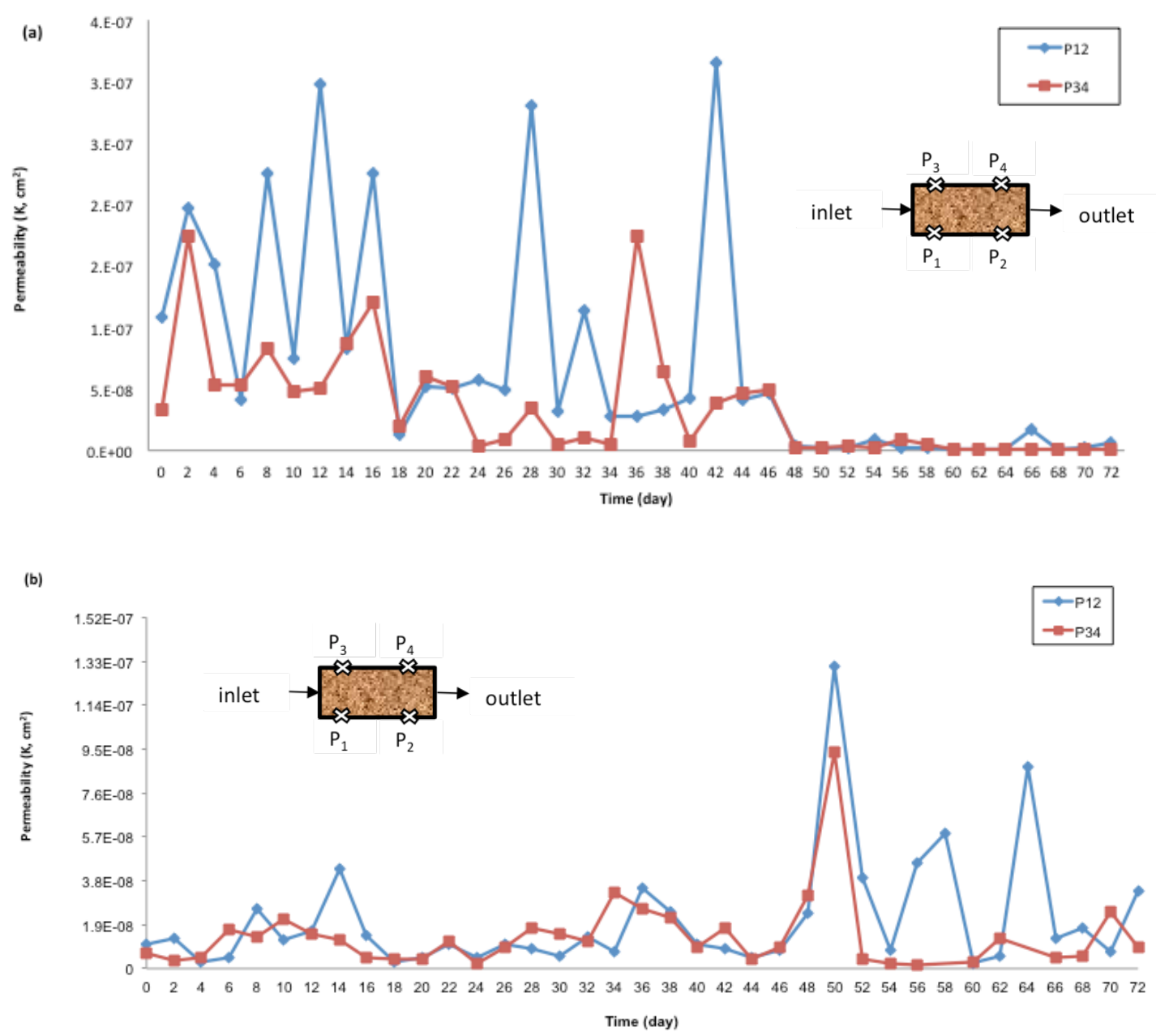

Figure 13: A plot of permeability $\left(\mathrm{cm}^{2}\right)$ versus time (day) for (a) coarse ZVI particle and (b) fine $Z V I$ particle from small scale experiments

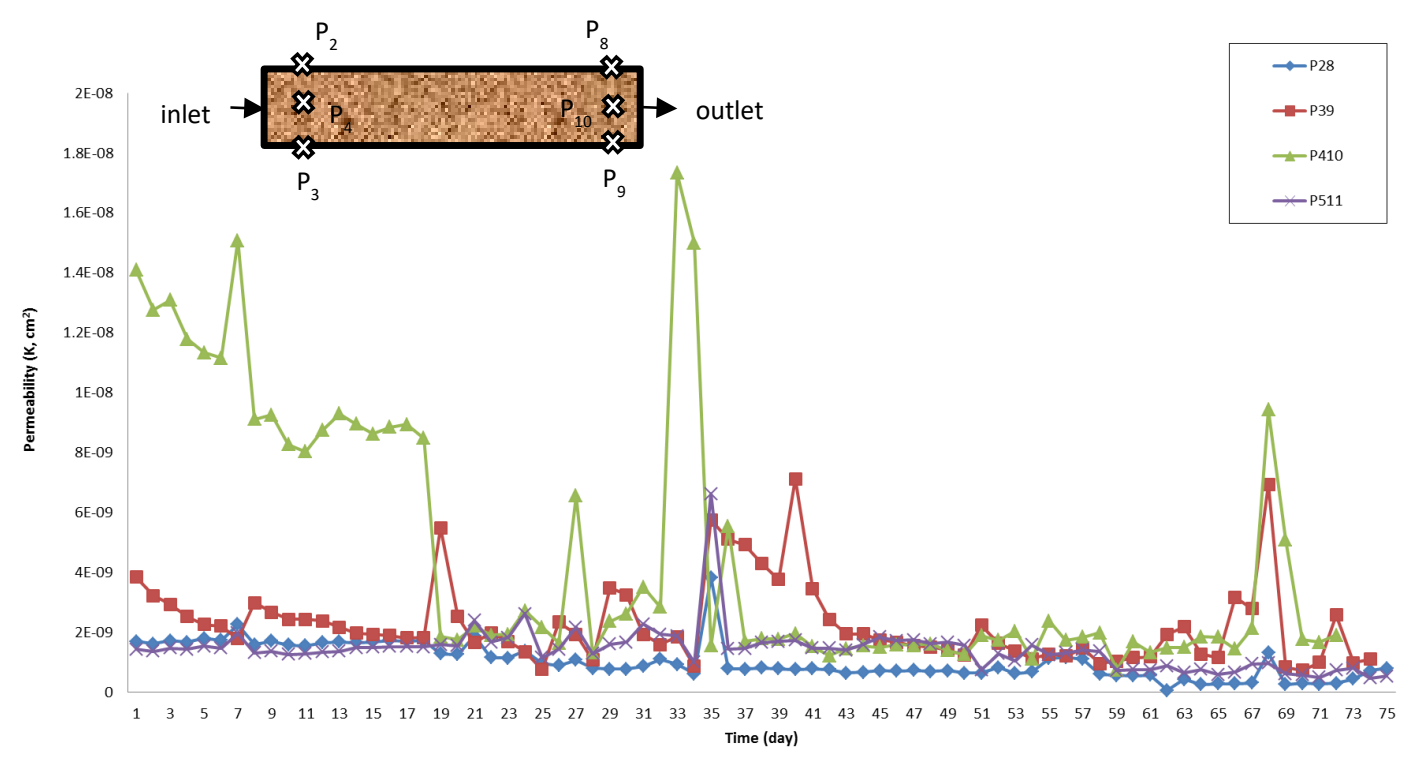

Figure 14: A plot of permeability $\left(\mathrm{cm}^{2}\right)$ versus time (day) for fine $\mathrm{ZVI}$ particle from large scale experiment 
Table 2: Summary of initial and final permeability values for small and large scale experiments

\begin{tabular}{|c|c|c|c|c|c|c|}
\hline & \multicolumn{3}{|c|}{ Small scale experiment } & \multicolumn{3}{|c|}{ Large scale experiment } \\
\hline & \multicolumn{3}{|c|}{ Permeability $\left(k, \mathrm{~cm}^{2}\right)$} & \multicolumn{3}{|c|}{ Permeability $\left(\mathrm{k}, \mathrm{cm}^{2}\right)$} \\
\hline & Location & Initial & Final & Location & Initial & Final \\
\hline \multirow{2}{*}{$\begin{array}{l}\text { Coarse } \\
\text { particle }\end{array}$} & P12 & $1.07 \mathrm{E}-7$ & $5.83 \mathrm{E}-9$ & & & \\
\hline & P34 & $3.37 E-8$ & $3.54 \mathrm{E}-10$ & & & \\
\hline Average & & $7.04 \mathrm{E}-8$ & $3.09 \mathrm{E}-9$ & & & \\
\hline \multirow{4}{*}{$\begin{array}{l}\text { Fine } \\
\text { particle }\end{array}$} & P12 & $1.03 \mathrm{E}-8$ & $3.33 \mathrm{E}-8$ & $\mathrm{P} 28$ & $1.70 \mathrm{E}-9$ & $7.97 \mathrm{E}-10$ \\
\hline & P34 & $6.47 \mathrm{E}-9$ & $9.2 \mathrm{E}-9$ & P39 & $3.84 \mathrm{E}-9$ & 1.10E-9 \\
\hline & & & & P410 & $1.41 \mathrm{E}-8$ & $1.90 \mathrm{E}-9$ \\
\hline & & & & P511 & $1.42 \mathrm{E}-9$ & $5.40 \mathrm{E}-10$ \\
\hline Average & & 8.39E-9 & $2.12 \mathrm{E}-8$ & & $5.27 \mathrm{E}-9$ & $1.08 \mathrm{E}-9$ \\
\hline
\end{tabular}

\subsection{Dimensional Analysis}

In order to carry out a dimensional analysis of the permeability loss, we substitute the experimental data into the dimensionless equation (6) and use the curve fitting tool in MATLAB (Matrix Laboratory, Cleve Moler, the MathWorks Inc., Natick, Massachusetts, United States) to plot the relationships between $\pi_{1}$ and $\pi_{2}$. The permeability values substituted in the equation are taken from the previous experiments, i.e., see section 3.4. Figure 15 shows that the relationship between the two dimensionless groups is a straight line, which implies that irrespective of the nature of the experiments and permeability values, the relationship between the dimensionless groups would be a linear relationship. In the plot of the experimental data, it can be seen that the permeability value follows a non-linear trend when viewed at different time periods. However, the non-dimensional analysis and the curve fitting exercise confirm that the relationship has a linear form.

From the small scale permeability data substitution, the particle size does not play any roles as both fine and coarse ZVI particles and data from all eight reference points provide the same slope of straight line, i.e., 2.42, as shown in the graph in Figure 15. The nondimensional equation that governs the behaviour is given as follows.

$$
\frac{k}{\Delta x^{2}}=2.42\left(\frac{\mu Q}{\Delta x^{3} \Delta P}\right)
$$

Figure 16 shows a plot of the dimensionless groups for large scale experiment. The data are taken from different pressure measuring points in the axial direction. Like the small scale, it can be seen from the results that the slope is the same in all of the four reference points with a value of 31.29. The non-dimensional equation that governs the behaviour in this case is given as follows.

$$
\frac{k}{\Delta x^{2}}=31.29\left(\frac{\mu Q}{\Delta x^{3} \Delta P}\right)
$$




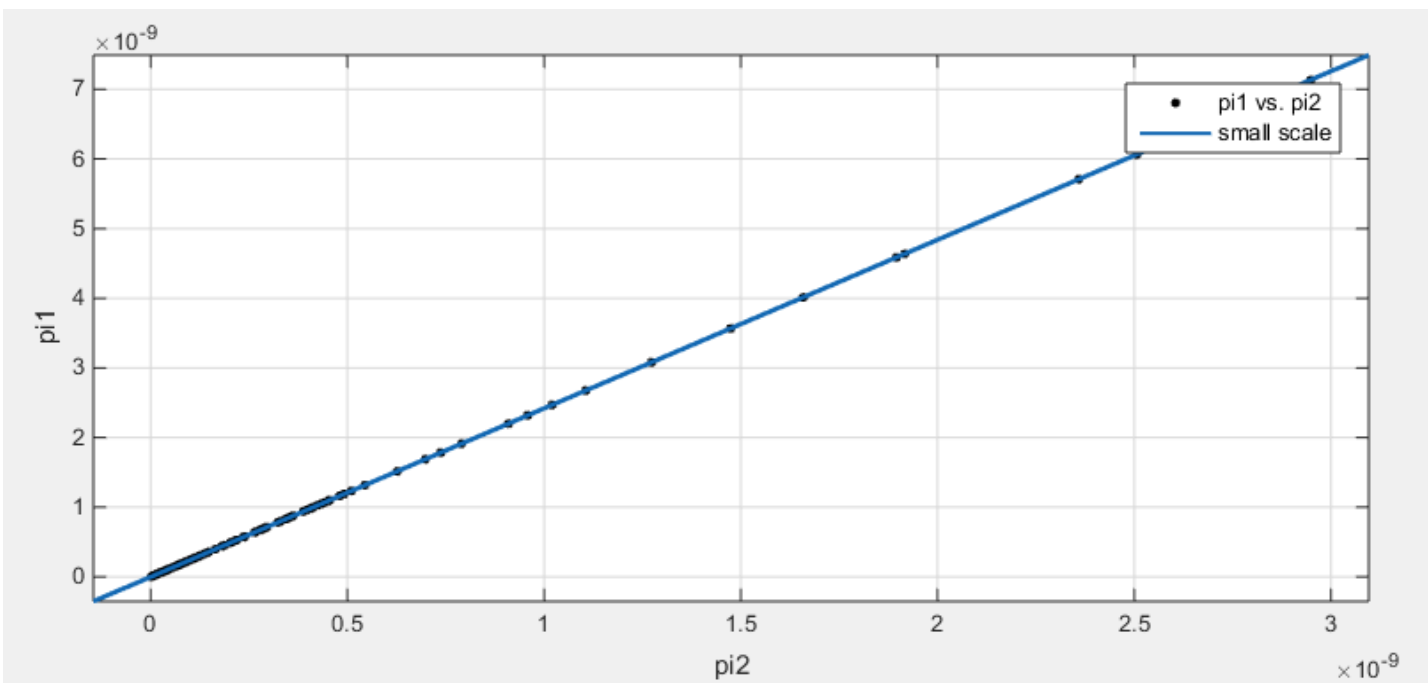

Figure 15: The plot of dimensionless group of $\pi_{1}$ (pi1) and $\pi_{2}$ (pi2) from small scale experiment at each pressure measuring points

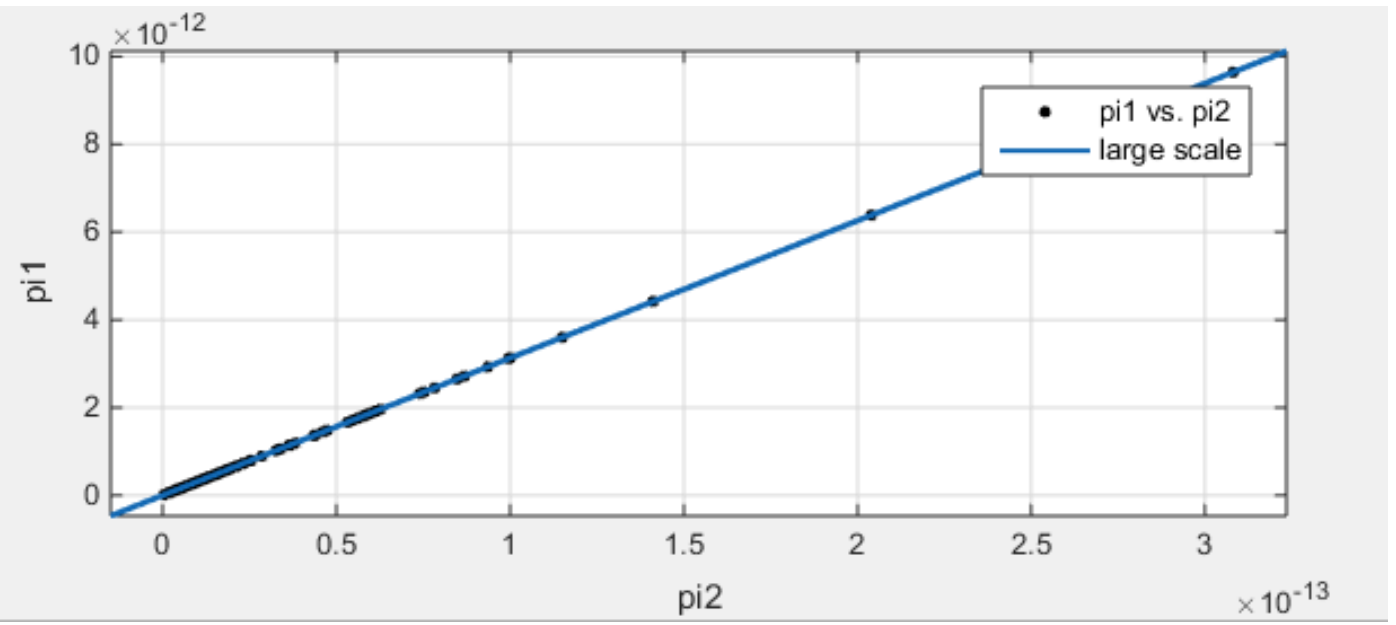

Figure 16: The plot of dimensionless group of $\pi_{1}$ (pi1) and $\pi_{2}$ (pi2) from large scale experiment at each pressure measuring points

As the slope is higher in the plot from large scale, i.e. slope of 31.29 and 2.42 in large and small scales, respectively, it can be assumed that in large scale, $\pi_{1}$ is changing with respect to $\pi_{2}$ at a higher rate than that of the small scale. The parameter in $\pi_{2}$ that was not kept constant is $\Delta \mathrm{P}$, this is in line with the previous section that there are more fluctuations in large scale rig due to the larger size of the rig, thus causing the higher changes in $\Delta \mathrm{P}$, which in turns, resulting in a higher slope.

Another issue that needs to be noted is that theoretically the slope from both small and large scale should be equal (in absence of permeably reduction and/or corrosion) as they are the results from the similar kind of experiment or basically, they are the permeability values from ZVI-PRB. However, from the results previously discussed, they are slightly different which suggest different rate of permeability losses at different scale. In order to understand the overall behaviour, the data from both small and large scales were combined to define a single slope to be the representative of ZVI-PRB. The result indicated that the slope is 2.42 , i.e. the equation is $y=2.42 x$ with the correlation coefficient $\left(R^{2}\right)$ of 1 , 
as shown in Figure 17. It is obvious that the small scale data are dominant in this combination as the slope of the mixed data is equal to that of the small scale, i.e. 2.42. Looking at these, the values from the large scale rig are negligible compared to those from small scale rig. The parameters in the $\pi$ term causing the direct impacts in this aspect are (1) distance between two pressure points $(\Delta x)$ and (2) pressure changes $(\Delta P)$. As the large scale rig is approximately 7 times larger than the small scale rig, the distance between 2 pressure points $(\Delta x)$ is much greater in large scale than that of the small scale. $\Delta x$ is the denominator in both $\pi$ terms $\left(\pi_{1}\right.$ and $\left.\pi_{2}\right)$ so it causes the final $\pi$ terms values to be much smaller than that of the small scale. In term of pressure changes $(\Delta P)$, as there are more fluctuations in the large scale domain, the pressure changes fall in the range of hundredthousandth whereas it is only in the hundredth range for the small scale. Again, $\Delta P$ is in the denominator of $\pi_{2}$ term, it also causes the smaller values of final $\pi_{2}$ term for large rig.

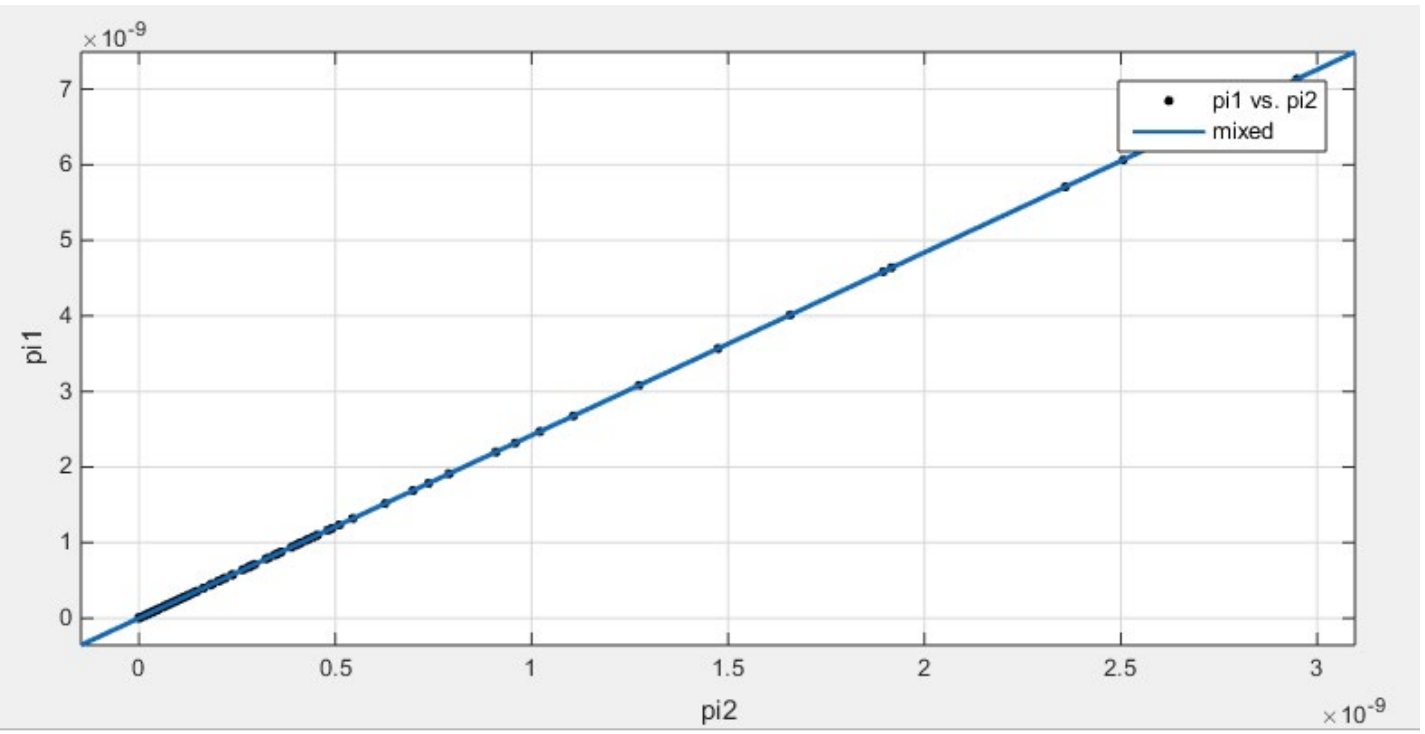

Figure 17: The plot of dimensionless group of $\pi_{1}$ and $\pi_{2}$ from small and large scale experiments at each pressure measuring points

\section{Conclusions}

It is evident from the experimental results that the permeability has declined through time as a result of the iron corrosion. After the $\mathrm{ZVI}$ has been in contact with the fluid, the reaction undergoes which alters the structure of the $\mathrm{ZVI}$ particles and reduces overall porosity and permeability. Theoretically, the particle size should get larger due to the precipitates or the corrosion of the iron that is the results of the reaction between $\mathrm{ZVI}$ and the fluids. The iron corrosion has been inspected by XRD and it can be identified that the corrosion products are maghemite and magnetite. The flow experiments indicated that the permeability value has been significantly reduced for coarse particle, e.g., in small scale experiment, it reduced from $7.04 \mathrm{E}-8$ to $3.09 \mathrm{E}-9 \mathrm{~cm}^{2}$.

It can be concluded that the pressure plays a major role in pointing out the direction of permeability losses. There is the preferential flow which can be identified by the change in pressure. The results might suggest that the pressure required for flow to take place through the PRB should be increased with time as there is significant mineral precipitation and, hence, drop in permeability. However, this may not be possible in the subsurface 
where the mineral precipitation may cause complete blockage and failure of the PRB as it is based on the concept of passive flow of groundwater. Our findings imply that the dimensionless equation can be applied for design of PRB apart from the understandings of the physico-chemical properties of the system which can support in terms of accurate comprehension at various scales of PRB.

\section{Acknowledgements}

The authors would like to thank Tony Eyre, Dave Smith, Robert Bentham, Dr Sandie Dann and Dr Jorgelina Farias for their experimental support and Connelly-GPM, Inc. for zerovalent iron materials support. This study was carried out with the funds from Ministry of Science and Technology of Thailand and Department of Chemical Engineering, Loughborough University, UK.

\section{References}

Abidoye L, Das D. 2014. Scale dependent dynamic capillary pressure effect for two-phase flow in porous media. Advances in Water Resources 74:212-230. DOI: 10.1016/j.advwatres.2014.09.009

Battelle 1998. Performance evaluation of a pilot scale permeable reactive barrier at former Naval Air Station Moffett Field, Mountain View, California, Naval Facilities Engineering Service Center: Port Hueneme, CA; 191.

Battelle 2000. Design guidance for application of permeable reactive barriers for groundwater remediation, Tyndall Air Force Base: Florida; 240. [accessed online at: https://www.clu-in.org/conf/itrc/prbll 061506/prb-2.pdf on May 2012]

Bergendahl J, Grasso D. 2003. Mechanistic basis for particle detachment from granular media. Environmental Science and Technology 37(10):2317-2322. DOI: 10.1021/es0209316

Chandrappa R, Das D. 2014. Sustainable Water Engineering: Theory and Practice. Wiley International: Singapore; 402.

Cundy A, Hopkinson L, Whitby R. 2008. Use of iron-based technologies in contaminated land and groundwater remediation: a review. Science of the Total Environment 400:42-51. DOI: 10.1016/j.scitotenv.2008.07.002

Das D. 2002. Hydrodynamic modelling for groundwater flow through permeable reactive barriers. Hydrological Processes 16:3393-3418. DOI: 10.1002/hyp.1107

Furukawa Y, Kim J, Watkins J, Wilkin R. 2002. Formation of ferrihydrite and associated iron corrosion products in permeable reactive barriers of zero-valent iron. Environmental Science and Technology 36(24):5469-5475. DOI: 10.1021/es025533h

Henderson A, Demond A. 2007. Long-term performance of zero-valent iron permeable reactive barriers: a critical review. Environmental Engineering Science 24:401-423. DOI: 10.1089/ees.2006.0071 
Henderson AD, Demon AH. 2013. Permeability of iron sulphide (FeS)-based materials for groundwater remediation. Water Research 47:1267-1276. DOI: 10.1016/j.watres.2012.11.044

Holdich R. 2002. Fundamentals of Particle Technology. Midland Information Technology and Publishing: Loughborough, U.K.; 173.

Huang G, Liu F, Yang Y, Deng W, Li S, Huang Y, Kong, X. 2015. Removal of ammoniumnitrogen from groundwater using a fully passive permeable reactive barrier with oxygenreleasing compound and clinoptilolite. Journal of Environmental Management 154:1-7. DOI: 10.1016/j.jenvman.2015.02.012

Jeen S.-W, Amos R, Blowes D. 2012. Modeling gas formation and mineral precipitation in a granular iron column. Environmental Science and Technology 46:6742-6749. DOI: 10.1021/es300299r

Jeen S.-W, Gillham R, Blowes D. 2006. Effects of carbonate precipitates on long-term performance of granular iron for reductive dechlorination of TCE. Environmental Science and Technology 40(20):6432-6437. DOI: 10.1021/es0608747

Junyapoon S. 2005. Use of zero-valent iron for wastewater treatment. KMITL Sci. Tech. Journal 5(3):587-595.

Kamolpornwijit W, Liang L, West O, Moline R, Sullivan A. 2003. Preferential flow path development and its influence on long-term PRB performance: column study. Journal of Contaminant Hydrology 66(3-4):161-178. DOI: 10.1016/S0169-7722(03)00031-7

Kaveh-Baghbaderani B, Nassehi V, Kulkarni A. 2009. Three dimensional modelling of interaction between surface and Darcy flow regimes through soils. Water Science and Technology 60 (7) :1911-1918. DOI: 10.2166/wst.2009.577

Kim S, Kamala-Kannan S, Lee K.-J, Park Y.-J, Shea P, Lee W.-H, Kim H.-M, Oh B.-T. 2013. Removal of $\mathrm{Pb}$ (II) from aqueous solution by a zeolite-nanoscale zero-valent iron composite. Chemical Engineering Journal 217:54-60. DOI: 10.1016/j.cej.2012.11.097

Kohn T, Livi K, Roberts A, Vikesland P. 2005. Longevity of granular iron in groundwater treatment processes: corrosion product development. Environmental Science and Technology 39:2867-2879. DOI: 10.1021/es048851k

Li L, Benson C, Lawson E. 2005. Impact of mineral fouling on hydraulic behavior of permeable reactive barriers. Ground Water 43(4):582-596. DOI: 10.1111/j.17456584.2005.0042.x

Li Z.-J, Wang L, Yuan L.-Y, Xiao C.-L, Mei L, Zheng L.-R, Zhang J, Yang J.-H, Zhao Y.-L, Zhu Z.T, Chai Z.-F, Shi W.-Q. 2015. Efficient removal of uranium from aqueous solution by zerovalent iron nanoparticle and its graphene composite. Journal of Hazardous Materials 290:26-33. DOI: 10.1016/j.jhazmat.2015.02.028 
Luo $\mathbf{H}$, Jin $\mathbf{S}$, Fallgren $\mathbf{P}$, Colberg $\mathbf{P}$, Johnson $\mathbf{P}$. 2010. Prevention of iron passivation and enhancement of nitrate reduction by electron supplementation. Chemical Engineering Journal 160(1):185-189. DOI: 10.1016/j.desal.2006.04.023

Ma R, Cai C, Li Z, Wang J, Xiao T, Peng G, Yang W. 2015. Evaluation of soil aggregate microstructure and stability under wetting and drying cycles in two Ultisols using synchrotron-based X-ray microcomputed tomography. Soil and Tillage Research 149:1-11. DOI: 10.1016/j.still.2014.12.016

Mackenzie P, Horney D, Sivavec T. 1999. Mineral precipitation and porosity losses in granular iron columns. Journal of Hazardous Materials 68(1):1-17. DOI: 10.1016/S03043894(99)00029-1

Phillips D, Van Nooten T, Bastiaens L, Russell M, Dickson K, Plant S, Ahad J, Newton T, Elliot T, Kalin R. 2010. Ten year performance evaluation of a field-scale zero-valent iron permeable reactive barrier installed to remediate trichloroethene contaminated groundwater. Environmental Science and Technology 44(10):3861-3869. DOI: 10.1021/es902737t

Powell R, Blowes D, Gillham R, Schultz D, Sivavee T, Puls R, Vogan J, Powell P, Landis R. 1998. Permeable reactive barrier technologies for contaminant remediation. U.S. EPA Remedial Technology Fact Sheet. EPA 600/R-98/125. [accessed online at: https://cluin.org/download/rtdf/prb/reactbar.pdf on April 2012]

Reardon E. 1995. Anaerobic corrosion of granular iron: measurement and interpretation of hydrogen evolution rates. Environmental Science and Technology 29:2936-2945. DOI: 10.1021/es00012a008

Ruhl A, Franz G, Gernert U, Jekel M. 2014. Corrosion product and precipitate distribution in two-component Fe(0) permeable reactive barriers. Chemical Engineering Journal 239:26-32. DOI: 10.1016/j.cej.2013.11.017

Ruhl A, Jekel M. 2012. Impacts of $\mathrm{Fe}(0)$ grain sizes and grain size distributions in permeable reactive barriers. Chemical Engineering Journal 213:245-250. DOI: 10.1016/j.cej.2012.10.007

Ruhl A, Kotre C, Gernert U, Jekel M. 2011. Identification, quantification and localization of secondary minerals in mixed Fe-0 fixed bed reactors. Chemical Engineering Journal 178:210-216. DOI: 10.1016/j.cej.2011.06.067

Ruhl A, Unal N, Jekel M. 2013. Combination of $\mathrm{Fe}(0)$ with additional reactive materials in fixed bed reactors for TCE removal. Chemical Engineering Journal 222:180-185. DOI: 10.1016/j.cej.2013.02.059

Thiruvenkatachari R, Vigneswaran S, Naidu R. 2008. Permeable reactive barrier for groundwater remediation. Journal of Industrial and Engineering Chemistry 14:145-156. DOI: 10.1016/j.jiec.2007.10.001

Wilkin R, Puls R, Sewell G. 2003. Long-term performance of permeable reactive barriers using zero-valent iron: geochemical and microbiological effects. Ground Water 41(4):493503. DOI: 10.1111/j.1745-6584.2003.tb02383.x 
Yin W, Wu J, Huang W, Wei C. 2015. Enhanced nitrobenzene removal and column longevity by coupled abiotic and biotic processes in zero-valent iron column. Chemical Engineering Journal 259:417-423. DOI: 10.1016/j.cej.2014.08.040

Zhang $Y$ and Gillham R. 2005. Effects of gas generation and precipitates on performance of Fe0 PRBs. Groundwater 43:113-121. DOI: 10.1111/j.1745-6584.2005.tb02290.x 